This is a so-called personal version (author's manuscript as accepted for publishing after the review process but prior to layout and copyediting) of the article: Granqvist, $N$. and Laurila, J. (2011). Rage against self-replicating machines: Framing science and fiction in the US nanotechnology field. Organization Studies 32 (2): 253-280. Researchers are kindly asked to use the official publication in references.

\title{
RAGE AGAINST SELF-REPLICATING MACHINES: FRAMING SCIENCE AND FICTION IN THE US NANOTECHNOLOGY FIELD
}

\author{
Nina Granqvist \\ Department of Management \\ Aalto School of Economics \\ P.O. Box 21230 \\ FI - 00076 Aalto \\ nina.granqvist@aalto.fi \\ Juha Laurila \\ Department of Management \\ Turku School of Economics \\ Rehtorinpellonkatu 3 \\ FI - 20500 Turku \\ juha.laurila@tse.fi
}




\begin{abstract}
Research in the sociology of science has increasingly begun to acknowledge the role that external influences play in shaping the boundaries and content of science. However, a scarce understanding still prevails with regard to the role of peripheral, popular movements in the emergence of scientific fields, and of professional fields in general. Through their attention to boundary work, scientific fields also provide a fruitful, yet neglected context to study how actors engage in efforts to alter frames in order to adjust and negotiate community boundaries. This qualitative study of the emergence of the US nanotechnology field from 1986 to 2005 makes several contributions to knowledge about these issues. First, our study shows that peripheral, popular movements open up avenues for scientific fields by generating understanding and receptivity for novel ideas through story-telling, which gives rise to their cultural embeddedness. Second, we find that by capitalizing on such culturally embedded concepts, scientists make science particularly vulnerable to external interventions, limiting the effect of boundary work. Third, the study shows how usually persistent hierarchies between communities are tested, challenged, and reproduced in an emerging professional field. The study therefore provides understanding on how actors in the key communities are able to use framing to negotiate their positions and community boundaries within a complex, emergent field.
\end{abstract}

Keywords: boundary work, framing, field emergence, nanotechnology, scientific field, professional field 


\section{INTRODUCTION}

The science fiction and magic of today are the science and technology of tomorrow. - Arthur C. Clarke

How do novel scientific fields come about, and what role do movements peripheral to science play in this process? Studies in sociology of science have directed attention to various social and cultural processes that shape the contents and boundaries of science, largely focusing on internal influences. The research on scientific and intellectual movements (SIMs), in particular, provides a prominent framework for investigating the emergence of scientific disciplines. It outlines how heterodox movements in science challenge dominant paradigms from within, and how such movements, despite opposition, may survive and reach acceptance as a novel discipline (Frickel and Gross 2005; Jacobs and Frickel 2009). On the other hand, the literature on boundary work gives attention to external influences by concentrating on those demarcation activities in which scientists engage in order to protect the integrity of science from attacks by outsiders, and to maintain the monopoly for scientists to define what counts as science (Gaziano 1996; Gieryn 1983; Gieryn et al. 1985; Ramsden 2002). However, these studies have tended to conceptualize non-scientific influences as something that scientists successfully rule out. Most attention in this approach, therefore, has been directed at what is excluded from the realm of science on the grounds that it represents pseudo-science, religion, engineering, or politics (Gieryn 1983; Moore 1996). Although the studies on scientific and intellectual movements and on boundary work both acknowledge the complex connections between science and society at large, they do surprisingly little to problematize the role of non-scientific activities in the emergence and institutionalization of scientific fields. 
There are, however, other bodies of research that have begun to address this very issue. First, studies have investigated how environmental movements (Frickel 2004), AIDS activism (Epstein 1996), the emancipation of women (Boxer 1998), and the fight for social justice by African-Americans (Small 1999) have transformed both natural and social sciences by giving rise to novel disciplines. This research has shown how social movements and their consequent cultural and political embeddedness have blurred the boundaries between laypeople and experts regarding who has the leverage to define the direction and contributions of science (Epstein 1996, Rojas 2007). Second, studies addressing the relationship between political and funding institutions, and science, show that the cultural and political embeddedness of scientific concepts and research areas (Jasanoff 1987; Oreskes 2003; Slayton 2007) give rise to discursive struggles through which scientists try to maintain their credibility (Kinchy and Kleinmann 2003) and professional identity (Burri 2008), while engaging in political activity. In this view, scientists are not only regarded as protectors of science, but also as self-interested and politically savvy actors with “competing, complex, and overlapping social commitments” (Moore 1996: 1595-96). This research stresses that scientists interact with political constituents both within and outside of science, and reframe their message in order to resonate with the grievances of each audience (Frickel 2004; Frickel and Gross 2005; Gieryn et al. 1985). Albeit reluctantly, they often engage in the popularization of science by using unscientific rhetoric in order to gain access to public support and funding (Jasanoff 1987; Mellor 2003, Oreskes 2003). According to Scott et al. (2000), even actors in natural sciences and medicine use interpretively loose concepts to describe their activities and grievances. 
With regard to examining the emergence of novel scientific fields, these observations on the opportunistic and interpretive use of scientific and popular concepts underline the role of framing activities in the transformation of such professional contexts. Framing refers to a process by which individuals actively construct and articulate schemata of interpretation that enable them to order and make sense of various events (Benford and Snow 2000; Goffman 1974; Stevenson and Greenberg 2000). Frames give rise to some actions becoming deemed more appropriate than others (Lounsbury et al. 2003). Therefore, framing in general, and the creation of collective action frames in particular, is important in emerging fields, where fierce competition over both meaning and access to resources prevail (Aldrich and Fiol 1994, Lounsbury et al. 2003). In such contexts, ambiguity allows many frames to coexist in different communities (Rao et al. 2000) and locations (Ritvala and Granqvist 2009), and makes it hard to estimate which of them become dominant. With regards to scientific fields, Collins (2000) defines them as consisting of a community of active researchers, publication outlets, and dedicated institutional and material resources. However, amidst the emergence of a scientific field it is unclear who should belong to the novel community of researchers, and when and by what means the dedicated resources for the field come about. As a result, in such context scientists face the simultaneous challenge of framing a field to make it understandable to, and to create resonance among, both internal and external audiences; while at the same time engaging in boundary work so as to protect it from what they consider harmful influences.

Despite such intriguing challenges, the role of peripheral movements in framing and boundary drawing in emerging scientific fields has been granted insufficient attention. First, previous research on the impact of social movements and other societal actors to science does not fully cover various cultural and political influences. While studies indicate 
that science, and the futurist and science fiction movements are in interaction (Kirby 2003; Kline 2009; Mellor 2003; 2007), and that idea entrepreneurs and management "gurus" play an important role in renewing various organizational domains (Gill and Whittle 1992, Jackson 2001, David and Strang 2006), there is scarce understanding on the particular processes through which such peripheral or popular movements influence the formation of highly professional fields. Second, while previous studies have begun to address framing processes in field emergence (Lounsbury et al. 2003; Maguire et al. 2004, Rao et al. 2000), this research has largely focused on how frames are employed to mobilize meaning and resources, and has tended to overlook how actors engage in efforts to alter frames in order to adjust and negotiate community boundaries. As outlined above, community boundaries have a particular role within scientific fields, which therefore form a suitable context for investigating these processes.

To address each of the issues highlighted above, our study draws on an extensive analysis of the US nanotechnology field from 1986 to 2005. Nanotechnology provides an intriguing empirical research context because a wide array of actors has been involved in its formation. The concept and some key ideas were formulated by futurists and nurtured within the science fiction community. Despite such origins, nanotechnology became a conceptual umbrella for varying activities across several natural sciences and was legitimated by the launch of National Nanotechnology Initiative (NNI) in 2000. We identify three distinct framing phases during the period under investigation. The first of these is characterized by futurist envisioning of the inevitable, dystopian and utopian outcomes of the trend of miniaturization; the second by strong cultural dissemination of the futurist framing, and the growing interest among scientists for its political co-optation; and the third by domination of scientists through reframing several existing activities into the 
realm of what had become mainstream nanotechnology, and the consequent marginalization of the futurist community. Nanotechnology, therefore, provides a revelatory case on the interplay between fiction, policy, and science, and on the relationship between framing and boundary drawing activities during the emergence of a scientific field.

Our research makes several contributions to understanding the role of peripheral movements, and the dynamics of framing and boundary work in scientific fields, with implications also for other professional contexts. First, our study shows that futurist and fiction movements may fundamentally influence the birth of scientific fields. This mainly occurs indirectly by these peripheral actors generating initial understandings and receptivity for novel ideas among government and the wider public through story-telling, giving rise to their cultural embeddedness; and only secondarily by the means of direct interaction between the peripheral and incumbent communities, here, scientists. Second, we demonstrate how the capitalizing upon such culturally embedded concepts makes the emerging field particularly susceptible to external interventions, and challenges the leverage of scientists’ boundary drawing, which the extant research has typically assumed to be effective. We therefore show that cultural resources for legitimation may also originate from varying sources within such professional contexts, and that they play a role in challenging the prevailing power relationships between communities, however temporarily. Third, we find that boundary work forms an important aspect of framing in professional fields where hierarchies among communities largely define their legitimacy. By studying how actors in participating communities negotiate their positions and community boundaries as an on-going process, we contribute to the development of a nuanced, relational approach on framing in complex, emergent professional fields. 
In the remainder of the paper we first introduce our research design, empirical material and methods for analysis. This is followed by the detailed longitudinal analysis of the emergence of the US nanotechnology field, which is divided into three consecutive periods covering the development during two decades. The final section presents the main contributions of the study, and ends with suggestions for future research.

\section{METHODOLOGICAL APPROACH}

Our study of the US nanotechnology field during 1986-2005 explores the processes through which ideas initially nurtured by futurist and science fiction communities contributed to the launch of a prestigious nanotechnology initiative, and later gave rise to the marginalization of the futurist community. The focus on the futurist and scientific communities is warranted because their activities created the foundations for further framings for nanotechnology among other communities, including those representing science fiction, government, and business. The initial futurist framing referred to a specific scenario of self-replicating intelligent nanomachines. It created expectations of a groundbreaking, revolutionary technology with enormous possibilities, but also tremendous risks. In contrast, the scientific community stressed the trend of miniaturization, where nanotechnology referred to activities reaching to 1-100 nanometers; in other words, the size scale of a billionth of a meter. In 2000, the launch of the National Nanotechnology Initiative (NNI) was the key signal that nanotechnology had begun to signify a wide array of natural science research in this size scale. 
Similar to Lounsbury et al. (2003) and Washington (2004), we develop a narrative that analyzes the framing activities that resulted in such a shift of meanings, participation, and power relationships in the field. To investigate this process, we use several data sources, which is typical for intensive case studies (Butler 1997; Numagami 1998; Stake 2005). Our research draws on the analysis of an extensive body of interview and archival material that aims to map how various actors participated in the framing of meaning for nanotechnology; what was the role of each framing, and how they evolved over time; and what consequences each framing had for nanotechnology developing into a scientific field.

We began our investigation by conducting 16 semi-structured, open-ended interviews between March and May 2006. The informants included government officials and lobbyists involved with nanotechnology, pioneering scientists, and representatives of the futurist community. The interviews helped us form a general understanding of the development of the field. From the analysis we identified the critical actors and junctures in the emergence of nanotechnology, including key events in its the formation, the main framings and their proponents, the contestations that took place, and overall, the events leading to the launch of the NNI. However, the role of the interviews in our analysis was more explorative than confirmatory, and we acknowledge that they alone cannot provide sufficient historical accounts. Therefore, we collected an extensive set of archival data from four different sources in order to systematically examine the framing process and its outcomes.

Table 1 details our data and the quality of evidence that each dataset provides for the framing stages. The table shows that the amount of evidence originating from different sources increases as more players enter the field. Interview and media data cover the entire period, and together with the futurist archival data they form the key source to study the early stage. The data from scientific and government communities cover also the later 
stages of field development. Therefore, the table, for its part, describes the participation of different communities to field development during the consecutive periods.

\section{$<$ TABLE 1 ABOUT HERE >}

The first step of our analysis was to cover the framing activities of futurists. For that purpose, we carried out content analysis of 52 Foresight Updates, a Foresight Institute newsletter published quarterly in most years during 1987-2005. The typical length of each newsletter was 20 pages; resulting in over 1000 pages of text for analysis. Although edited by the futurist community, the newsletter uncovers a broad range of activities in the development of nanotechnology with a focus on related advances in science. Table 1 describes the sections which the newsletters regularly covered. In addition to such standard sections, the editorial team reported a large variety of other relevant issues in nanotechnology and related domains. We analyzed each article, and copied the texts that we considered relevant to tracking the framing activities to a separate file, resulting in 580 pages of text for further analysis. As a result of this second-round analysis we produced a document presenting the varying formulations of the concept of nanotechnology, the key framing events, and the overall developments of the field that were reported by the newsletters. This document then acted as one empirical source for writing the narrative.

Second, in terms of the scientific community, we analyzed how nanotechnology was addressed in the journal Science during the period under investigation. We chose Science because it is the key academic journal for those disciplines that played a major role at the early stages of nanotechnology emergence; that is, physics and chemistry. To map how the related activities were framed among scientists we reviewed texts where nanotechnology 
had been discussed in other than purely academic pieces of research. To achieve this, we used the search words nanotech* and nanoscien*1 ${ }^{1}$ to search for entries in the sections described in Table 1. A total of 262 news stories published between 1991 and 2005 were collected for content analysis. We analyzed each news story to identify the actors that it discussed, the framing of nanotechnology that it advocated, and the potential contestation and boundary work activities that it portrayed. An outcome of the content analysis was a document covering the main events relating to the framing of nanotechnology among scientists during the period under investigation.

We supplemented the content analysis of Science with the analyses of the nanotechnology special issues in Scientific American in September 2001, and IEEE Technology and Society Magazine in winter 2004, as well as the Point-Counterpoint debate between futurist Eric Drexler and chemist Richard Smalley in Chemical and Engineering News reported on December 1, 2003. These particular materials did not only mediate the debate over nanotechnology to wider audiences, but also indicated the key framings and proponents of these framings. The latter debate can also be considered a critical boundary drawing event indicating the marginalization of the futurist meanings of nanotechnology in science.

In order to study how other actors responded to the futurist and scientific framings we collected two more sets of archival data. The first of these consists of the transcripts of Congressional Hearings. This material revealed the individuals who were chosen to represent and endorse nanotechnology, and the framings that were presented at each point in time. These hearings acted as key framing events in the sense that the boundaries of nanotechnology were drawn and contested by various participating actors at the highest governmental level. In the selection of relevant hearings we used the search word "nano" to 
identify those in which the concept appeared regularly throughout the transcript ${ }^{2}$. We omitted hearings in which "nano" appeared only in referencing information, biographies of participants, or as a general reference to future technologies; in other words when it was used as a 'throw-away' technology label ${ }^{3}$. Such hearings were disregarded because they contribute little to the framing of meaning of nanotechnology. These premises led us to select twelve Congressional Hearings from the total of 21, resulting in 1583 pages of text for analysis. The hearings took place between June, 1992 and June, 2005. We analyzed the documents by coding who were present in hearings, what kind of expressions they used when framing nanotechnology, and how these changed over time.

Our fourth set of archival data consisted of media coverage on nanotechnology during the period under investigation. This data provided supplementary evidence on the changing meanings and positions of different actors advocating and using the nanotechnology concept. According to Mellor (2003), particular constructions of science dominate the media landscape in such a way that texts become stabilized and self-replicating because they begin to increasingly refer to each other. In a sense, these particular discourses about science become institutionalized (Phillips et al. 2004), which is then reflected in the relatively narrow repertoire through which the media represents science. Thus, the analysis of media texts provided information on the relative popularity of futurist, scientific, and other framings in the media. We searched for the words "nanotech*” and "nanoscien*” among the major US news and business publications found in the Factiva and LexisNexis databases. The basis of sampling of the newspaper articles was to select the first articles on the $1^{\text {st }}$ and the $15^{\text {th }}$ day of the month, or closest date thereafter. For the years with less than 24 hits, all news articles were selected. This sampling resulted in the total of 327 news items for analysis. We then created a database within which each article was given an 
identification number on the basis of the order of publication. The news items were carefully read and analyzed in two rounds. We coded articles with information regarding the actor(s) who were addressed (11 different categories were identified). We also produced a short description of the main contents of each article. Through this analysis we gained an understanding of how the media reported different framings of nanotechnology, and how this reporting changed over time.

As the final step of our data collection we gathered other social scientific studies and reports on nanotechnology (e.g. Mody 2004a; 2004b; 2006; Toumey 2005; 2007; Choi and Mody 2009) and compared and refined our observations of the development of nanotechnology field against these sources. Illustrative quotes of the framing and boundary drawing activities by different actors from the data are provided in the analysis that follows.

\section{FRAMING THE BOUNDARIES OF THE US NANOTECHNOLOGY FIELD, 1986-2005}

\section{Scientific and cultural roots of nanotechnology}

The contemporary field of nanotechnology has strong scientific and cultural roots, which go well beyond the mid-1980s when the nanotechnology concept was first introduced. In science, miniaturization has proceeded within several disciplines. In microelectronics, the

exponential shrinking of electronic components, as predicted by Moore's Law ${ }^{4}$, paved the way for modern-day computing (cf. Choi and Mody 2009), and resulted in the emergence of microtechnology from the 1960s onwards, and microelectromechanical systems (MEMS) in electronics in the 1980s. In physics, the invention of the scanning tunnelling 
microscope (STM) in 1981, and the atomic force microscope (AFM) in 1986, allowed researchers to see and to operate with individual atoms for the first time. In chemistry, the recognition of the field of supra-molecular chemistry in 1987 focused the attention on molecular-level interactions. Later, inventions of new forms of carbon, such as fullerenes and carbon nanotubes, as well as the discovery of single electron transistors and molecular switches, are further examples of important breakthroughs in materials and components at the nanoscale.

Since the 1950s, such developments in miniaturization increasingly inspired science fictionists. While miniaturization and small worlds have been a standard theme in the science fiction genre since its inception, at least eight science fiction books ${ }^{5}$ had been published by the mid-1980s that may be viewed as predecessors of the later futurist notions of nanotechnology, in particular. Small worlds have also been addressed in other popular culture with broader and more varied audiences; for example in Fantastic Voyage (1966) and Innerspace (1987). These movies depict the shrinking of people, which enables them to travel in a vessel through the veins in a human body to conduct research and microscopic surgery. Thus, the idea and potential of miniaturization has formed a part of imagery in popular culture for decades, and has thereby disseminated ideas of the small size scale among the wider public. Table 2 presents the key developments in both the popular culture and scientific and the policy domains from the 1950s until 2005.

$<$ INSERT TABLE 2 ABOUT HERE $>$

Prior to the mid-1980s, science and fiction about miniaturization largely occupied separate societal niches. However, crossings of this border also took place. Scientists who 
have been inspired by the fiction of miniaturization include the Nobel Laureate physicist Richard Feynman, who voiced ideas about the possibilities of the manipulation of matter on atomic scale in a 1959 conference dinner speech “There is Plenty of Room at the Bottom”. Retrospectively, this speech has been framed as the initial formulation of nanotechnology (Toumey 2005; 2008). From the 1980s onwards, the extant scientific and cultural embeddedness of miniaturization, together with the growing visibility and importance of microtechnology through the development of personal computing, offered substantial momentum to the political acceptance of nanotechnology as the inevitable future path towards the sub-micron world. Therefore, the concept provided potential for building connections not only across different disciplines involved with sub-micron research, but also across the separate social domains of science and fiction. The next sections set out to analyze the framing and boundary drawing activities, stretching over two decades, which resulted in nanotechnology moving from the domain of fiction to the realm of science by 2000, attracting several billions of dollars of annual funding across the globe. Table 3 provides a summary of the changing frames for nanotechnology across the period under investigation.

\section{Formation of the self-replication and sub-micron-scale driven framings for nanotechnology, 1986 to the early 1990s}

Eric Drexler has widely been given the credit for inventing and popularizing the concept of nanotechnology ${ }^{6}$. Studying the activities of Drexler and the Foresight Institute, an NGO established to promote radical ideas on and responsible development of nanotechnology, thus provides us with a starting point for the development of the entire field. The idea of 
nanotechnology has its origins in the affiliations that Drexler held during his studies. Many of his associates at the time were members of the L5 Society, a futurist association established in 1975 to investigate and promote space colony ideas; or were affiliated with the Massachusetts Institute of Technology (MIT), where Drexler conducted his undergraduate and graduate studies and later also doctoral research, obtaining a Ph.D. in 1991. Such influence resulted in that the Drexlerian take on nanotechnology was inherently futuristic by nature (Mody 2004b). In an interview that appeared in the first issue of Foresight Update (June 15, 1987) Drexler described his early interests and activities in the area as follows:

For many years I'd been concerned about technology and the future, and had been looking at what could be built with tools that we didn't have yet. My work at MIT had focused on what we could build in space once we had inexpensive space transportation and industrial facilities in orbit. ... I'd been following a variety of fields in science and technology, including the work in molecular biology, genetic engineering, and so forth. I had been impressed by the fact that biological systems were based on molecular machines and that we were learning to design and build these sorts of things. This got me thinking about what sorts of things we could build when we got good at designing molecules. And this led pretty rapidly to the idea of self-assembling systems of molecules that could act as molecular machines - and the idea of molecular machines that could build other molecular machines. This was in the spring of 1977.

The early interests of Drexler revolved around space exploration which, when combined with his reading of work on molecular and genetic engineering, provided the inspiration to envision the possibilities of self-assembly in this context. In 1979, Drexler came across Feynman’s “Plenty of Room” speech which anticipated important breakthroughs in science and technology to which miniaturization could give rise. This speech resonated with the ideas that Drexler was developing at the time. The article on molecular engineering published in a relatively esteemed scholarly outlet (Drexler 1981) was an initial formulation of what he would later label as nanotechnology. Reflecting his engineering background, the 
article drew an analogy comparing the parts of cells with those of machines. An important feature of this paper was that it presented the largely forgotten speech of Feynman as the initial formulation of Molecular Nanotechnology (Toumey 2008). It was possible for Drexler to establish this connection and thereby obtain credibility for his ideas largely because Feynman's speech had a futurist flavor and lacked such precision that it could have been used to invalidate his claims.

\section{$<$ TABLE 3 ABOUT HERE >}

Among the first steps to disseminate his ideas, Drexler presented a lecture series on nanotechnology at MIT in 1984. The lectures gave rise to the MIT Nanotechnology Study Group, which Drexler formed in January 1985 as a means to discuss the possibilities and risks of Molecular Nanotechnology (MNT) (Update 1, 1987). The term nanotechnology was launched to the wider audience in 1986 when Drexler published his book "Engines of Creation: The Coming Era of Nanotechnology” (see also Table 3). The book had a strong engineering tone in that it presented nanotechnology as the future of manufacturing with amazing potential to build anything synthetically, atom-up, through self-replication. According to the book, manufacturing by such means would result in, for example, endless riches and abundance, much longer or even eternal life through cell repair and cryogenics, and the possibility to colonize space. However, should the self-replication process go out of control and allow the small assemblers consume all the resources in the world, the Earth would become a dead planet, filled with "gray goo" of self-replicating machines. The key aspect of the Drexlerian framing is that through the regulation of nanotechnology the materialization of dystopian risks could perhaps be avoided. The Drexlerian framing was 
thus characterized by a combination of enormous benefits on the one hand, and devastating threats on the other, as well as the claim that the development towards nanotechnology was inevitable (cf. Mody 2004a).

The Engines of Creation was the key means to disseminate the futurist frame of nanotechnology to the public. To support the spread of the message, Drexler gave dozens of lectures across the US, which "ranged from technical presentations at universities to corporate seminars to talks for general audiences” (Update 1, June 15, 1987). Furthermore, in 1986, the same year that the book appeared, Drexler and his wife Christine Peterson established the Foresight Institute, a non-profit organization, to inform the public about Molecular Nanotechnology. In our interview an early member of the futurist community described the forming of the Institute as follows:

His book [...] laid out the basic technological possibilities and also the policy issues that appeared to be at that time. At that stage, [we] could see that this was going to be a very big deal. The people that read the book would want more information. So, in the back of the book it says, 'Please contact Foresight Institute' ... Many people contacted us [...] that was the initial founding.

A relatively tightly-knit futurist community consisting mostly of engineers formed around Foresight Institute. According to the informant above, for this community nanotechnology "was about atomically precise construction and in a particular scenario ... it was a coherent body of knowledge that many people shared”. The Foresight Institute's task was to educate people to both the possibilities and dangers of nanotechnology, although the Institute also had an interest in other themes, such as artificial intelligence, life extension, and space (Update 1, June 15, 1987). The key ways employed to disseminate the community's view on nanotechnology were through symposia and conferences. The community held the first MIT nanotechnology symposium in 1987, and the first Foresight 
Technical Conference followed in 1989. The first conferences mainly brought together the futurist community, but some interested scientists also participated in order to contemplate the potential of nanotechnology research. As a first attempt to embed nanotechnology in the university curricula, Drexler organized a ten-week course on Nanotechnology and Explorative Engineering in 1988 at Stanford University. To create structural forms around nanotechnology, in 1991 Drexler, joined by some Silicon Valley business executives, established the Institute for Molecular Manufacturing, a sister organization to the Foresight Institute, that provided small grants for nanotechnology research. In 1993 the Foresight Institute began to award Feynman Prizes to individuals doing 'a great job' for nanotechnology, in order to strengthen the connection between the community and the legacy of Richard Feynman.

The academic affiliations of the key members of both institutes were an important means for legitimating their activities. Drexler, for example, was affiliated to prominent universities (the Artificial Intelligence Laboratory at MIT, and Stanford). Although these strategies were successful when dealing with the media, Drexler and his colleagues had not gained the support of the wider scientific community, which remained more or less indifferent to such ideas about nanotechnology. During the late 1980s and early 1990s the few scientists who had heard of nanotechnology considered it science fiction. However, Drexler, as a visible futurist with visions on the technologies beyond the micron scale, was able to gain a foothold in Congressional foresight activities. In 1990, the Congressional Office of Technology Assessment initiated a study of the future of miniaturization. The primary focus was on microelectronics and micro-machines, but the project was expanded to also address molecular approaches. A workshop was organized as a part of the study, and “of fifteen invited participants, two represented the molecular perspective” (Update 11, 
March 15 1991), albeit only Drexler was a Foresight futurist. However, such inclusion marks an initial recognition of Molecular Nanotechnology at the governmental level.

Following the initial encounters with governmental organizations, Drexler and Peterson added a further component to the Foresight Institute framing. They addressed "the expected environmental benefits of using Molecular Nanotechnology to replace today's relatively inefficient and dirty manufacturing processes” at the World Economic Forum in Davos (Update 8, 15 March 1990). Resulting from such an augmented framing, and initial legitimacy within policy, Drexler was invited to testify at the 1992 Congressional hearing on "New Technologies for a Sustainable World", chaired by Vice President Al Gore. At this occasion, Drexler continued to present Molecular Nanotechnology as a clean manufacturing technology with groundbreaking potential to solve pollution problems.

Among the scientific community, the concept of nanotechnology, although not its futurist meanings, generated some resonance almost immediately after its introduction. This was largely because the concept connoted the development beyond microtechnology. In its October 1987 call for funding, The National Physical Laboratory in the U.K. was perhaps the first academic institution to define nanotechnology as the manufacture and measurement of devices and products in the size scale between 0.1-100 nanometers (see Table 3). At the same time, a Japanese research initiative, the Human Frontier Science Program, with a focus on artificial intelligence and nanotechnology, also stressed the submicron definition of nanotechnology (Update 1, 15 June 1987). These events manifest the malleability of the concept itself, which enabled prominent scientists to create a competing, resonant framing. Such a definition of nanotechnology marks the initial point of the legitimation of the concept within science. 
The surfacing of an alternative framing for nanotechnology did not go unnoticed by the Foresight community. In their view, the scale-centered "broader, British meaning" with which nanotechnology was connoted in science violated the original idea of Molecular Nanotechnology (Foresight Update 8, 15 March 1990). The Foresight community members thus recognized that their framing for nanotechnology was under attack and that there would be a constant need to draw boundaries with regard to the use of the concept by others.

$<$ FIGURE 1 ABOUT HERE $>$

According to our analysis of the news coverage (Figure 1), during 1986-1991 the media mostly disseminated the futurist framing of nanotechnology to the wider public. As a result, the Drexlerian framing of Molecular Nanotechnology dominated the emerging public discourse in the late 1980s. Owing to its science fiction and engineering origins, the Drexlerian framing, with its utopian and dystopian connotations and futurist rhetoric, generated most resonance among other futurist and science fiction communities. Our analysis of the media data shows this clearly: many of the news stories in this period consisted of reviews of science fiction novels, most of which described a dark world of the future where nanotechnology had, in one way or another, changed the premises of human existence. While the Foresight Institute made a distinction between their own ideas and those presented in nanotechnology-generated science fiction literature by labeling it as "nanotek" (Update 8, 15 March 1990), the Foresight community had a generally positive attitude towards the sci-fi use of the concept. From their perspective, the popular cultural adoption of nanotechnology facilitated the wider societal dissemination of the Drexlerian 
framing, and increased the understanding of its possibilities and risks among the wider public. The focus on self-replicating machines and dystopian visions resulted in that scientists kept their distance from Molecular Nanotechnology. However, the size scale driven framing had begun to gain acceptance among scientists and policymakers, and the framing contests around nanotechnology began to intensify.

\section{Cultural embedding of the futurist framing and its co-optation by scientists, the early 1990s to 1999}

All through the 1990s, Foresight Institute members continued their active dissemination of the molecular manufacturing perspective on nanotechnology. In addition to the quarterly newsletters, Foresight futurists continued to give speeches on nanotechnology in various events across the country. They published several books (e.g. Drexler et al. 1991; Crandall and Lewis 1992; Krummenaker and Lewis 1995), of which Drexler’s (1992) Nanosystems won the Association of American Publishers' annual award for the best computer science book in 1992. During this period, the annual Foresight Conferences gained popularity as they transformed from a small by-invitation-only gathering in 1989 (Update 5, 1 March 1989) into an open event peaking with over 500 participants in 2001 (Update 47, 31 December 2001). While most of the members of the Foresight Institute had a background in engineering, through the conferences the Institute was able to create contacts to the scientific community. By the late 1990s, the conference keynote speakers included prominent scientists who had or would later receive a Nobel Prize, such as Fraser Stoddart and Richard Smalley in 1995, Smalley again in 1997, and Physicist Steven Chu in 1998. Such appearances indicated that the conferences were deemed to have scientific relevance, 
which provided credibility and legitimacy for the Foresight futurists among the wider public and media. The Foresight Institute established also awards to motivate people to make contributions to nanotechnology, including the \$250 000 Feynman Grand Prize for Major Advances in Molecular Nanotechnology (Update 24, 15 April 1996).

Based on the disseminating activities, the Drexlerian views, together with their extensions in science fiction, continued to dominate the media coverage of nanotechnology during most of the 1990s (Figure 1). Again, a substantial number of the news entries throughout the 1990s were reviews of sci-fi books. Owing to the futurist nature of the Drexlerian framing, as well as its increasing adoption by science fiction authors, it was no surprise that most scientists who had heard about Molecular Nanotechnology thought that it had no scientific foundation whatsoever, and that such ideas were "wrong at best, dangerous at worse” (Toumey 2005: 22). However, the emerging interest at the government level, together with the development of science in, for example, atomic microscopy, opened up new opportunities for the scientific community. As a result, an increasing number of scientists began to consider nanotechnology to be a useful concept referring to sub-micron research (cf. Mody 2004a). In our interview a physicist described the state of affairs as follows:

I think the word nanotechnology became legitimate probably by the mid-90s. There was this early period in the late 80s, early 90s where there wasn't someone like Smalley or Steve Chu. They call up and say "oh, we are gonna use nanotechnology, yes there is some people who view this as a miraculous wonder technology and all, but they can sort of have their conferences and motivate extreme future things. Maybe that is good ... we'll start some journals." So once it became a field, there was a lot of it.

The first journal called Nanotechnology was established in 1990, followed by Nanostructured Materials in 1992. Their editors and editorial boards consisted of members 
of the academic community, and both journals followed standard policies and procedures of scholarly publications. Scientists in physics and chemistry particularly drove the adoption of nanotechnology in science, the key advocate being chemist Richard Smalley. He had already formed a nanotechnology initiative in 1992 at Rice University, where undergraduate students from six departments, including chemistry, physics, and chemical engineering, had begun to work cooperatively and received multidisciplinary training (Science, 4 November 1994). These research activities were formalized in 1996 with the launch of the Rice Center for Nanoscale Science and Engineering. In the same year Smalley also received the Nobel Prize for the discovery of fullerenes, a soccer ball shaped structural form of carbon. The award was a major legitimating event for Smalley as a spokesperson for nanotechnology, and also for the entire emerging academic field.

Smalley later acknowledged that Drexler's conception of nanotechnology inspired him to engage in the field in the first place (Science and Engineering News, December 1, 2003). Smalley’s later public framing of the concept borrowed from the futurist, utopian rhetoric with the aim to generate interest and enthusiasm about the future potential of nanotechnology. On the other hand, he stressed the role of scientific tradition and physical laws about what it is possible to achieve, and rejected the futurist notions of self-replicating machines. To add to the confusion of framings, Smalley and the scientific community talked about self-replication in scientific terms, which did not help the non-scientific audience make a difference between the futurist and scientific notions of self-replication. Such controversy characterized the scientists' framing activities overall. In their quest to gain political acceptance for the size-scale driven framing during the late 1990s, scientists themselves heavily blurred the boundaries between science and fiction (cf. Table 4), despite 
being aware of the potential threat of accusations of pseudo-science (cf. Roco 2007). As a pioneering physicist described in an interview:

I guess there has been a lot of hyping way beyond Drexler by people, who work in the research community attempting to get the major funding initiative that President Clinton signed off [in 2000].

The participation of prominent members of the scientific community, as well as increasing momentum around computing and miniaturization during the 1990s, resulted in further involvement of the science policy actors. This was crucial for the wider dissemination and legitimation of the concept of nanotechnology at the governmental level. According to Roco (2007), the National Science Foundation (NSF) had already started "creating a chorus” in the form of research funding to support nanotechnology in 1990, followed by a series of informal and formal activities among science and science policy communities toward the mid-1990s (see Table 2). The formal attempts at the governmental level to coordinate work on nanoscale research and development began in November 1996. From that point on, the representatives of several federal science agencies held regular meetings to discuss their plans and programs for nanotechnology. This series of meetings resulted in a major legitimating event: the founding of the Interagency Working Group on Nanotechnology (IWGN) under the direction of the National Science and Technology Council in September 1998. Over the subsequent two years several published reports and events (Table 2) represent the flow of activities that legitimated and disseminated the scientific framing of nanotechnology as a distinctive scholarly and policy domain in the US. The June 1999 Congressional Hearing "Nanotechnology: The State of Nanoscience and Its Prospects the Next Decade” signposted the governmental preparation for the National Nanotechnology Initiative. 
However, perhaps a key issue for such a rapid governmental recognition of nanotechnology was that it resonated with the political need to reallocate US science funding resources. In an interview a key science policy lobbyist depicted the context that facilitated the rapid adoption of the concept among scientists as follows:

...there was a lot of concern within the scientific community about the imbalance between biomedical research and physical sciences and engineering. NIH [National Institutes of Health] was ensuring very strong support to double its budget over a five-year period. Biomedical research was increasing but for physics, chemistry, engineering was stagnant. The National Nanotechnology Initiative was one way of getting the public in the Congress and elected officials excited about investing in the physical science and engineering.

The lobbyist explained that during the 1990s the dominance of biomedicine over other natural sciences and engineering had caused concern among some scientific and policy communities. Nanotechnology was considered a way to tilt this balance to the benefit of physics and engineering. As a result, from 1999 onwards several science policy lobbyists ${ }^{7}$ began to inform various members of the White House of the potential of nanotechnology, and of the long-term benefits related to investing in the area.

Taken together, such framing activities and political motivations resulted in the forming of the National Nanotechnology Initiative (NNI), a multibillion dollar research program, which President Clinton announced in his speech at the California Institute of Technology in January 2000. The speech manifests the influence of the Drexlerian framing for example by referring to Feynman as the founding father of nanotechnology: “Over 40 years ago ... Feynman asked, what would happen if we could arrange atoms one by one the way we want them?” The launch of NNI marked the formal acknowledgement of nanotechnology as a distinctive domain in science and science policy, and legitimated the term as a conceptual umbrella for a large body of sub-micron research within science. 
Owing to such governmental and scientific interest during the latter half of the 1990s, the Foresight community struggled to guard the boundaries of nanotechnology and adopted two strategies. Firstly, they strove to return the concept to its original meanings; that is, to refer to the particular scenario involving self-replicating machines and their role in generating utopian and dystopian futures. However, despite these attempts, when nanotechnology turned into a fashionable concept in science and policy, the Foresight framing became increasingly marginalized in both governmental and scientific domains. The consequent second strategy was to take distance from the nanotechnology concept by inventing other terms, stressing the engineering vision. As stated by Christine Peterson (Update 32, March 15, 1998):

Again, this was expected: sexy terminology gets picked up by wannabes looking for funding, forcing the rest of us to come up with new terms for our goals: nanotechnology, molecular nanotechnology, molecular manufacturing... we'll probably have to keep migrating.

The Foresight community was well aware of the impact of their conceptual innovation of nanotechnology, and aimed to replicate the success by using other related concepts. The newsletters successively encouraged members to enact and develop a "memetic strategy" (Update 35, January 20, 1999) by using terms other than nanotechnology when talking to researchers, policymakers and the public about the Foresight goals; and then reporting the success of these encounters.

Resulting from these developments, at the turn of the millennium nanotechnology had become a politically legitimate scientific domain. Interestingly, however, the formation of the meanings and creation of its boundaries had not yet reached its peak. 


\section{Policy dominance of the scientific framing and marginalization of the futurist}

framing, 2000-2005

The launch of the National Nanotechnology Initiative had several consequences for the overall legitimacy of nanotechnology. First, the number of nanotechnology-related publications in key journals for the natural sciences grew exponentially between 2000 and 2005. Second, whereas there were about a dozen nanotechnology research centers in the US universities in 2000 (Science, 24 November 2000), their number multiplied in the following few years so that almost all major universities with natural sciences on their curricula formalized their activities on nanotechnology into programs and centers. Third, substantial funding began to flood to the area in the US, Europe and Asia alike. For example, both in the US and EU the public funding for nanotechnology research increased tenfold between 2000 and 2005 (President's Council of Advisors in Science and Technology 2005), and the growth of private funding was only slightly less substantial. Such a massive response to NNI was not surprising as its advocates from both the futurist and scientific communities had, in government hearings and the media, consistently framed nanotechnology as one of the key technology platforms of the $21^{\text {st }}$ century, with potential implications comparable to those of the steam engine, electric light, and electronic communication technologies. Together, the excitement and substantial investments turned nanotechnology into a highly fashionable concept in science and technology in the early 2000s. Such excitement is visible in the media analysis, which manifests the shift from reporting futurist and fiction activities to covering news in business and science (Figure 1). 
However, few actors had a clear understanding of the boundaries of nanotechnology in science; that is, the set of research activities and disciplines that should be associated with it. As written in Science special issue on nanotechnology (24 November 2000):

To a 5-year-old with a hammer, the world looks like a nail," adds Lester Lave, an economist at Carnegie Mellon University in Pittsburgh, who studies the development of technology. "Nanotechnology is a hammer, and nanotechnologists are looking around to see what they can hit with it.

Adoption of the broad, scale-dominated definition of nanotechnology embraced most natural sciences, but it did not help to draw clear boundaries for the emerging field. During the early 2000s the great majority of scientists involved with nanoscale research did not consider themselves as nanoscientists but rather, continued to describe themselves as researchers within their respective discipline (Mody 2006). For most researchers the nanotechnology concept remained too broad and unfocused to be useful. As reported by an interviewed physicist:

It's nice to have something so broad that failure is not an option ... it would be little like saying, "Will there be breakthroughs in chemistry in the next decade?" and the answer is yes. And nanotechnology is at least that broad, or broader.

This criticism of the lax boundaries of nanotechnology did not, however, prevent the scientific community from being relatively uniform on the occasions in which the sizedriven understanding of nanotechnology was to be communicated to external constituents and stakeholders. However, while many scientists had employed the futurist rhetoric to lobby the NNI, after its launch the utopian and dystopian visions posed a threat to the legitimacy and credibility of scientific nanotechnology research. The Frankenfood scenario, resulting in the ban of genetically modified organisms in Europe, was a fairly recent event. 
Such examples made scientists to recognize that public acceptance of nanotechnology was the key issue to secure future funding and development for the rapidly expanding field.

The need of the scientific community to take a clear stand towards the futurist molecular manufacturing vision on nanotechnology became increasingly evident during the early 2000s. Only a few months after the announcement of the NNI, Bill Joy, a co-founder of Sun Microsystems and a speaker at some Foresight Institute events, published his address "Why the Future Doesn’t Need Us” in the April 2000 issue of Wired Magazine. The article discussed the potential of nanotechnology which, together with other technologies, threatened to wipe out humanity. The article received worldwide media attention, and disseminated effectively the dystopian aspects of the futurist framing of nanotechnology. As written in Science (November 24, 2000):

Bill Joy is nobody's Luddite ... So when he argued that research into nanotechnology and other fields should be stopped before it wipes out humanity, humanity took notice.

This event was followed by the Foresight Institute, together with the Institute for Molecular Manufacturing, releasing Foresight Guidelines on Molecular Nanotechnology. The publication aimed to start "an open discussion about the appropriate framework within which to develop nanotechnology” (Update 41, 30 June 2000). Among the scientist camp, Joy’s warning received an outright rejection and the Foresight Guidelines were largely dismissed. For example, according to the article “Is nanotechnology dangerous?” in Science (24 November, 2000):

At first, stunned nanoscience researchers quietly shrugged off the [futurist] concerns. But more recently, they've begun to fight back, arguing vehemently at meetings that what Joy and others fear is at best implausible and more likely plain wrong. "The research community needs to divorce itself from the lunatic fringe," says Steven Block, a biophysicist at Stanford University in Palo Alto. 
The quote accentuates that ignoring the futurists, while at the same time borrowing from their framing of nanotechnology, was no longer a viable strategy for scientists. In 2001, the pressure on nanoscientists to make a clear distinction between the futurist and scientific framings was amplified by the publication of "The number one New York Times bestseller” fiction novel Prey by Michael Crichton. The novel told a story of how the escape of a swarm of nanomachines from a research laboratory led to devastating consequences. Prey was disseminated globally, with a first print of 1580000 copies. The book, together with the related story “Could Tiny Machines Rule the World?” in Parade, an insert magazine for more than 330 newspapers with a circulation of 36 million, effectively spread the futurist concerns of nanotechnology via the mass media (Update 51, April 2003). A further event that disseminated the futurist framing followed in January 2003, when ETC Group, a Canadian watchdog organization for socially responsible technology, released “The Big Down”, a report that referenced the futurist concerns. This resulted in large numbers of people, including Prince Charles of the UK, publicly expressing their concern about the problem of grey goo, "in which a swarm of millions of rapidly self-replicating microscopic robots, in a ravenous quest for fuel, would consume the entire biosphere until nothing remained but an immense, sludge-like robotic mass” (New York Times, September 11, 2003).

Scientists involved with nanotechnology research responded to this massive popular cultural dissemination and embedding of the futurist framing by attempting to redirect the attention to more plausible risks; for example toxicological harm caused by nanomaterials. In addition, the Greenpeace report on nanotechnology in July 2003, “Future Technologies, Today’s Choice”, disseminated a more science-based view about the risks, and set aside the dystopian visions. However, the legitimacy among, and support of, the wider public for 
nanotechnology was at stake. This is indicated by the many implications that the futurist framing of the risks of nanotechnology had at the government level. These resulted in the incorporation of ethical, legal, and social issues into government sponsored workshops and research (cf. Mody 2008). For example, the transcript of the 2003 Governmental Hearing, “Societal Implications of Nanotechnology” (p. 4) mentions Joy’s pamphlet and Crichton’s novel as important triggers for "the debate over the possible negative consequences of future developments in information technology, biotechnology, and nanotechnology”.

Increasing interest on the societal implications of nanotechnology provided a new temporary arena for the Foresight community to gain influence. Their research and other activities had become marginalized within the NNI scheme. This was instigated by the fact that they did not receive any governmental funding, which the community members recognized as a problem for the Institute’s overall legitimacy. The Foresight affiliates were initially able to gain a fairly strong ground in the discussions on nanosafety. For example, Christine Peterson and Ray Kurzweil, the latter being one of the best known and widely read futurists in the US and a supporter of the Foresight Institute, were invited to testify at the Congressional Hearing on "The Societal Implications of Nanotechnology" in April 2003. The transcript of the hearing shows that futurist framing on the long-term risks of nanotechnology dominated the discussion, at the cost of science-driven short and mid-term risks. These risks accentuated the notion of singularity, referring to a scenario where machine intelligence exceeds that of humans and begins to control its own destiny, much as depicted in the Terminator movies. As a stark contrast, the scientists' approach towards nanotechnology risks included the health and environmental effects of nanoparticles, such as fullerenes and nanotubes, as voiced by chemist Vicky Colvin. 
However, interestingly, futurists were not present in the major NNI workshop on “Nanotechnology: Societal Implications - Maximizing Benefit for Humanity” organized in December 2003. The report of this event focused on the potential risks related to nanomaterials, the social divide induced by technology, and the need for multidisciplinary education. At the same time, the futurist framing of the risks of nanotechnology was largely dismissed. The futurists, thus, also became gradually marginalized from government-level discussions on the societal implications of nanotechnology.

To better manage the public understanding of nanotechnology, scientists needed to communicate their framing more clearly to the wide public. During the early 2000s, scientists, including prominent chemists Richard Smalley, George Whitesides, and Charles Lieber, engaged in public debates on nanotechnology in order to convey the scientific sizescale driven framing, and undermining the futurist framing as "scary”, "fantasy" and "a dream” with no scientific foundations whatsoever (e.g. Smalley in the written testimony of the Congressional Hearing of 1999; see Table 2). Smalley became the most visible spokesperson of the scientific community on the matter. He continuously reminded the public of the chemical impossibility of manipulating individual atoms without affecting the surrounding ones, which stressed the unfeasibility of nano-sized self-replicating machines; the key aspect of the futurist framing. Smalley's formulations of the so-called "fat fingers” and "sticky fingers" problems for manipulating atoms were successively presented in the media. Examples include the Special Issues on nanotechnology in Science and in Scientific American in November 2000 and September 2001, respectively. Both of these special issues presented an extensive critique from several representatives of the scientific community against the futurist framing of nanotechnology in general, and individual futurists such as Eric Drexler, in particular. In 2003, Eric Drexler responded to these attacks 
in the form of an open letter to Smalley, published on Ray Kurzweil's website, which Smalley ignored. The second open letter, posted on the Foresight Institute website gave rise to the Chemical and Engineering News Point-Counterpoint debate between Smalley and Drexler in December 2003. This debate was extensively reported in the media, and finally opened up some of the controversies between the scientists' and futurists' framings of nanotechnology to the public.

Nevertheless, for laypeople, the scientific framing of nanotechnology was still difficult to understand due to the remaining contradictory elements. The members of the scientific and policy communities continued to hail nanotechnology as a revolutionary technology with the potential to change the world as we know it. This was a non-scientific tactic, which rhetorically connected them to the futurist framing. Furthermore, to nonscientist laypeople, the chemists' articulation of synthetic nanoscale organisms and selfreplication had some resemblance to the Drexlerian framing (cf. Mody 2004b). While scientists held entirely different meanings for these concepts, for the general public such distinctions were hard to grasp. In this sense, partly owing to the overall confusion about where to draw the boundaries of nanotechnology, the scientific framing lacked precision and was unable to draw clear boundaries towards the futurists. As a result of this, and the more general cultural embeddedness achieved through popular books and news stories, the futurist framing remained persistent among the wider public (cf. Mody 2008).

Despite being increasingly marginalized within the NNI scheme, the Foresight futurists still aimed to obtain research funding and to play a role in governmental science policy. The heavy critique by the scientific community, however, resulted in changes in their framing and messages about nanotechnology. Christine Peterson wrote in Update 53 (January 15, 2004) as follows: 
If we want a balanced discussion, the positive uses of MNT [Molecular Nanotechnology] need a lot more emphasis. Given our long-term goals, we're the natural choice to attempt to restore a balance to this worldwide debate. Therefore, close watchers of our message may notice a shift toward beneficial uses of MNT.

Both Peterson and Drexler stressed that the particularly controversial idea of selfreplication needed to be de-emphasized in order for the Foresight Institute message to be taken seriously. This resulted in the creation of New Foresight as announced in the newsletter in October 2005. The mission of New Foresight was "To ensure the beneficial implementation of nanotechnology” (Update 55, 13 October 2005). The long-term technology focus was complemented with a short and mid-term application focus in order to create resonance with basic and applied sciences. In this sense, the futurists now downplayed several of the distinctive characteristics of their initial nanotechnology framing.

The framing activities that we have described above cast light on the processes through which peripheral movements contributed to the emergence of nanotechnology as a scientific field in the US. As a result of these framings and their cultural embeddedness in different societal and cultural realms, the debates about the boundaries and future possibilities of nanotechnology continue even today (e.g. Fischer et al. 2008). In the final section of this paper, we formulate our contributions to the extant literature and provide suggestions for future research. 


\section{DISCUSSION AND CONCLUSIONS}

This study set out to examine the role of peripheral movements giving rise to framing activities and boundary work in the emergence of the US nanotechnology field. By mapping the developments through which nanotechnology moved from futurism and fiction to science and policy, our research makes several theoretical contributions. First, the study provides novel insights into the processes through which futurist and fiction movements influence science. We identified some direct interactions between futurists and scientists in conferences and policy forums. However, these were of lesser importance when compared to indirect influences through government interest and public excitement that resulted from the futurists' and fiction writers' envisioning of nanotechnology, and their consequent cultural dissemination. Such findings resonate with the previous studies that have found that storytelling plays an important role in facilitating the emergence of novel activities by making them "more familiar, understandable, acceptable, and thus more legitimate, to key constituencies” (Lounsbury and Glynn 2001: 550). Likewise, Mellor (2003: 509) asserted that "public images of science are constructed, legitimized, and challenged” through the presentation of inspiring stories in the popular media. More than merely demonstrating that the stories generated receptivity around nanotechnology, we show that, since its inception, cultural embedding of the futurist envisioning profoundly shaped the boundaries and substance of the emerging scientific field. Our study, thus, reveals that fiction-based framing may become an important source of legitimacy even in such highly professional fields as natural sciences. 
Second, the challenges that scientists encountered in their later boundary drawing between science and fiction reveals that the use of popular culturally embedded concepts in the framing of science is a double-edged sword. We show that scientists may gain access to new resources by capitalizing on widely disseminated and fashionable concepts that allow the coexistence of contradictory framings in different cultural realms. However, co-optation of such excited, nonscientific rhetoric may give rise to a perception of a 'compromised' novel field within the scientific community, and thereby jeopardizes its internal legitimacy (cf. also Frickel and Gross 2005, Gieryn 1983). If scientists do not consider the substance or the concept valid, they may either ceremonially adopt the label to gain access to resources (Zbaracki 1998; David and Strang 2006), or outright reject to participate. Moreover, the popular culturally embedded concepts make an emerging scientific field vulnerable to external interventions because the original non-scientific meanings continue to prevail in realms where scientists have little control. Rather than assuming boundary work as successful (Gieryn et al. 1983, Ramsden 2002), our research demonstrates that there are important limitations to the power of scientists' boundary work as an exclusion mechanism in culturally embedded fields. We also show that the participation of multiple communities in the formulation of varying framings embeds the novel meanings within several cultural domains, which generates a wider resonance for the emerging professional field within society. This increases the persistence of the field and has an impact on its potential to become widely institutionalized.

Third, the present study contributes to developing the conceptualization of framing activities as a tool that allows the actors and communities involved to define themselves in relation to each other in emerging contexts. Highly professional fields make the inherent hierarchies between different involved communities particularly visible (Abbott 1988, 
Greenwood and Suddaby 2006). Our study shows how these hierarchies are tested, challenged, and reproduced in an emerging professional field. In such context, peripheral communities may, at least temporarily, obtain an influential position through the kinds of framing activities in which they engage, and adjust those activities based on the field responses. In a similar manner, the incumbent communities need to formulate a frame that supports and reproduces their dominance in the field. In this sense various frames and framing activities are formed in relation to the evolving power relationships in the field (see also Lounsbury et al. 2003). As such, framing provides an opportunity for the communities involved to define their boundaries vis-à-vis others as an on-going process. Compared to the research that focuses on framing as a tool for strategic mobilization (Gamson and Mayer 1996; Snow et al. 1986), or as a process of contestation (Rao 1998; Kaplan 2008), our study joins the development of a more nuanced, relational view on how frames, communities, and framing activities co-evolve through negotiation and boundary drawing processes in a complex, emergent field.

Finally, by showing how the community boundaries become permeable and how the internal hierarchies are challenged by peripheral influences, we also open up a fresh perspective on the processes described in the research on management fads and fashions. Recent works in this area have studied how trendsetters and idea entrepreneurs contribute to the continuation and distinct turns in the trends within particular genres of fashion (e.g. Abrahamson and Eisenman 2008; David and Strang 2006; Whittle 2008). We extend this research by showing that even in the most professional contexts, there is great variation in the community-related norms and cultural resources on which actors may draw to construct and justify their causes, to materialize their interests, and to engage in political activity. Our study, thus, suggests that in such contexts even peripherally positioned actors may operate 
as

trendsetters and idea entrepreneurs if they have access to the necessary cultural resources. Moreover, we find that by exploiting these cultural resources they may extend their influence from that of merely modifying trends in existing domains to initiating entirely new organizational fields.

How do our findings then compare with previous research on framing processes in other similar contexts? When looking into the development of another science-based field, in biotechnology, multiple interpretations of the core activities and future potential existed, giving rise to different dominant framings over the three decades of the field development (Kaplan and Murray 2010). Moreover, public perceptions of risk significantly influenced the later regulation of biotechnology, for instance, in the form of the debate on 'Frankenfoods' (Schurman 2004). Similar findings have been obtained, for example, also in railway (Hutter 2001), airline (Poole and Butler 1999) and shipping industries (Hänninen and Laurila 2008). However, the early formation of biotechnology was dominated by the interplay between actors representing science, technology, and the marketplace, yielding permeable, but comparably distinct boundaries for the field. In contrast, nanotechnology originated from a mélange of conceptual innovation and science-political co-optation, which then facilitated the bundling of a broad range of ongoing science and technology activities under a novel banner - also covering several areas of biotechnology. Taken together, the observations from both the nanotechnology and biotechnology fields resonate with Frickel (2004: 270), who suggested that the emergence of scientific fields does not necessarily depend on Kuhnian path-breaking findings but, rather, on the re-framing and repositioning of “existing facts, theories and methods".

Overall, our study indicates that the interplay between futurist and fiction framing, on the one hand, and scientific or other incumbent framings, on the other, represents a more 
common and influential pattern in the birth of professional fields than that which has been previously acknowledged. Research on how the participation of various "gurus" influences community action and governmental policies in such contexts may shed new light on the changing relations between peripheral movements, policy, and professions in contemporary societies. We believe that future research in this area would greatly benefit from comparative empirical studies both between different societal settings and varying professional fields.

Acknowledgements: We would like to thank Raghu Garud, Stine Grodal, Michael Lounsbury, Kari Lilja, André Spicer, Huggy Rao, the participants of the OTREG Seminar at the Imperial College, London, January 2008; the participants of the Workshop on Cognitive Framing and Strategy-Making in Sannäs Manor, Finland, May 2008; and the anonymous reviewers of Organization Studies for valuable comments and advice on different versions of the study. 


\section{REFERENCES}

Abbott, Andrew

1988 The System of Professions: An Essay of the Division of Expert Labor. Chicago: The University of Chicago Press.

Abrahamson, Eric and Micki Eisenman

2008 'Employee-management techniques: Transient fads or trending fashions?' Administrative Science Quarterly 53/4: 719-744.

Aldrich, Howard and Marlene Fiol

1994 'Fools rush in? The Institutional context of industry construction'. Academy of Management Review 19/4: 645-670.

Benford, Robert. D. and David A. Snow

2000 'Framing processes and social movements: An overview and assessment'. Annual Review of Sociology 26: 611-639.

Boxer, Marilyn Jacoby

1998 When Women Ask the Questions: Creating Women’s Studies in America. Baltimore: John Hopkins University Press.

Burri, Regula V.

2008 'Doing distinctions: Boundary work and symbolic capital in radiology'. Social Studies of Science 38/1: 35-62.

Butler, Richard

1997 'Stories and experiments in social inquiry'. Organization Studies 18/6: 927-948.

Choi, Hyungsub \& Mody, Cyrus

2009 'The long history of molecular electronics: Microelectronic origins of nanotechnology’. Social Studies of Science 39/1, 11-50.

Collins, Harry M.

2000 'Surviving closure: Post-rejection adaptation and plurality in science'. American Sociological Review 65/6: 824-845.

Crandall, BC and James Lewis, eds.

1992 Nanotechnology: Research and Perspectives. Cambridge: The MIT Press.

David, Robert and David Strang

2006 'When fashion is fleeting: Transitory collective beliefs and the dynamics of TQM consulting'. Academy of Management Journal 49/2: 215-233. 
Drexler K. Eric

1981 'Molecular engineering: An approach to the development of general capabilities for molecular manipulation’. Proceedings of National Academy of Sciences 78/9: 52755278.

Drexler, K. Eric

1992 Nanosystems: Molecular Machines, Manufacturing and Computation. New York: Wiley Interscience.

Drexler, K. Eric, Christine Peterson and Gayle Pergamit

1991 Unbounding the Future: The Nanotechnology Revolution. New York: Quill.

Epstein, Steven

1996 Impure Science: AIDS, Activism, and the Politics of Knowledge. Berkeley and Los Angeles: University of California Press.

Fischer, Erik, Cynthia Selin and Jameson Wetmore (Eds.)

2008 The Yearbook on Nanotechnology in Society, Volume I: Presenting Futures. Springer Science +Business Media.

Frickel, Scott

2004 'Building an interdiscipline: Collective action framing and the rise of genetic toxicology’. Social Problems 51/2: 269-287.

Frickel, Scott and Neil Gross

2005 'A general theory of scientific/intellectual movements'. American Sociological Review 70 (April): 204-232.

Gamson William A. and David S. Meyer

1996 'The framing of political opportunity’ in Comparative Perspectives on Social Movements: Political Opportunities, Mobilizing Structures, and Cultural Framings. John McCarthy, Doug McAdam, and Meyer N. Zald, eds: 275-290. Cambridge: Cambridge University Press.

Gaziano, Emanuel

1996 'Ecological metaphors as scientific boundary work: Innovation and authority in interwar sociology and biology'. The American Journal of Sociology 101/4: 874907.

Gieryn, Thomas F.

1983 'Boundary-work and the demarcation of science from non-science: Strains and interests in professional ideologies of scientists'. American Sociological Review 48/6: 781-795.

Gieryn, Thomas F., George M. Bevins and Stephen C. Zehr

1985 'Professionalization of American scientists: Public science in the creation/evolution trials’. American Sociological Review 50/3: 392-409. 
Gill, John and Sue Whittle

1992 'Management by panacea: Accounting for transience'. Journal of Management Studies 30/2: 281-295.

Goffman, Erving

1974 Frame Analysis: An essay on the organization of the experience. New York: Harper Colophon.

Heinze, Thomas

2004 'Nanoscience and nanotechnology in Europe: Analysis of publications and patent applications including comparisons with the United States'. Nanotechnology Law \& Business 1/4: 427-447.

Hutter, Bridget M.

2001 Regulation and risk: Occupational health and safety on the railways. New York: Oxford University Press.

Hänninen, Hannu and Juha Laurila

2008 'Risk Regulation in the Baltic Sea Ferry Traffic: The Successive Failures of Bow Visor Technology’. Science, Technology, \& Human Values 33/6: 683-706.

Jackson, Brad

2001 Management Gurus and Management Fashions: A Dramatistic Inquiry. London: Routledge.

Jacobs, Jerry A. and Scott Frickel

2009 'Interdisciplinarity: A critical assessment'. Annual Review of Sociology 35: 43-65.

Jasanoff, Sheila

1987 'Contested boundaries in policy-relevant science'. Social Studies of Science 17: 195-230.

Kaplan, Sarah

2008 'Framing Contests: Making Strategy under Uncertainty'. Organization Science 19/5: 729-752.

Kaplan, Sarah and Fiona Murray

2010 'Entrepreneurship and the construction of value in biotechnology'. Research in the Sociology of Organizations 29: 107-147.

Kinchy, Abby J. and Daniel Lee Kleinman

2003 'Organizing credibility: Discursive and organizational orthodoxy on the borders of ecology and politics'. Social Studies of Science 33/6: 869-896. 
Kirby, David A.

2003 'Science consultants, fictional films, and scientific practice'. Social Studies of Science 33/2: 231-268.

Kline, Ronald

2009 'Where are cyborgs in cybernetics?' Social Studies of Science 39/3: 331-362.

Krummenaker, Markus and James Lewis (eds.)

1995 Prospects in nanotechnology: Toward molecular manufacturing. New York: John Wiley \& Sons, Inc.

Lounsbury, Michael and Mary Ann Glynn

2001 'Cultural entrepreneurship: Stories, legitimacy, and the acquisition of resources'. Strategic Management Journal 22: 545-564.

Lounsbury, Michael, Marc Ventresca, and Paul M. Hirsch

2003 'Social movements, field frames and industry emergence: A cultural-political perspective on US recycling’. Socio-Economic Review 1: 71-104.

Maguire, Steve, Cynthia Hardy and Thomas B. Lawrence

2004 'Institutional entrepreneurship in emerging fields: HIV/AIDS treatment advocacy in Canada’. Academy of Management Journal 47/5: 657-679.

Mellor, Felicity

2003 'Between fact and fiction: Demarcating science from non-science in popular physics books’. Social Studies of Science 33/4: 509-538.

Mellor, Felicity

2007 'Colliding worlds: Asteroid research and the legitimation of war in space'. Social Studies of Science 37/4: 499-531.

Mody, Cyrus M.

2004a 'How probe microscopists became nanotechnologists' in Discovering the Nanoscale. D. Baird, A. Nordmann and J. Schummer eds., 119-233. Amsterdam: IOS Press.

Mody, Cyrus M.

2004b 'Small, but determined: Technological determinism in nanoscience'. HYLE International Journal for Philosophy of Chemistry 10/2: 101-130.

Mody, Cyrus M.

2006 'Corporations, universities and instrumental communities: Commercializing probe microscopy, 1981-1996’. Technology and Culture 47: 56-80.

Mody, Cyrus M.

2008 'The larger world of nano’. Physics Today October: 38-44. 
Moore, Kelly

1996 'Organizing integrity: American science and the creation of public interest organizations, 1955-1975’. The American Journal of Sociology 101/6: 1592-1627.

Numagami, Tsuyoshi

1998 'The infeasibility of invariant laws in management studies: a reflective dialogue in defence of case studies.' Organization Science 9/1: 2-15.

Oreskes, Naomi

2003 'A context of motivation: US Navy Oceanographic research and the discovery of sea-floor hydrothermal vents’. Social Studies of Science 33/5: 697-742.

Phillips, Nelson, Thomas B. Lawrence and Cynthia Hardy

2004 'Discourse and institutions'. Academy of Management Review 29/4: 635-652.

Poole, Robert W. Jr. and Viggo Butler

1999 'Airline deregulation: The unfinished revolution'. Regulation 22/1: 44-51.

President's Council of Advisors in Science and Technology

2005 The National Nanotechnology Initiative at Five Years: Assessment and Recommendations of the National Nanotechnology Advisory Panel. Washington.

Ramsden, Edmund

2002 'Carving up population science: Eugenics, demography and the controversy over the "biological law" of population growth'. Social Studies of Science 32/5-6: 857899.

Rao, Hayagreeva

1998 'Caveat emptor: The construction of non-profit consumer watchdog organizations'. American Journal of Sociology 103: 912-961.

Rao, Hayagreeva, Calvin Morrill, and Mayer N. Zald

2000 'Power plays: How social movements and collective action create new organizational forms'. Research in Organizational Behavior 22: 239-282.

Ritvala, Tiina and Nina Granqvist

2009 'Institutional entrepreneurs and local embedding of global scientific ideas - The case of preventing heart disease in Finland'. Scandinavian Journal of Management 25/2: 133-145.

Roco, Mihail

2007 'National nanotechnology initiative: Past, present and future' in Handbook on Nanoscience, Engineering and Technology. W. A. Goddard, III, D. W. Brenner, S. E. Lyshevski and G. J. Iafrate, eds.: 3-1 - 3-25. London: Taylor and Francis. 
Rojas, Fabio

2007 From Black Power to Black Studies: How a Radical Social Movement Became an Academic Discipline. Baltimore, MD: John Hopkins University Press.

Scott, W. Richard, Martin Ruef, Peter Mendel, and Carol Caronna

2000 Institutional change and organizations: Transformation of a health care field. Chicago: University of Chicago Press.

Schurman, Rachel

2004 'Fighting "Frankenfoods": Industry opportunity structures and the efficacy of the anti-biotech movement in Western Europe‘. Social Problems 51/2: 243-268.

Slayton, Rebecca

2007 'Discursive choices: Boycotting Star Wars between science and politics'. Social Studies of Science 37/1: 27-66.

Small, Mario L.

1999 'Departmental conditions and the emergence of new disciplines: Two cases in the legitimation of African-American Studies’. Theory and Society 28: 659-707.

Snow, David A., E. Burke Rochford, Steven K. Worden and Robert D. Benford 1986 'Frame Alignment Processes, Micromobilization and Movement Participation'. American Sociological Review 51/4: 464-481.

Stake, Robert E.

2005 'Qualitative case studies' in The Sage Handbook of Qualitative Research. N. K. Denzin, and Y. S. Lincoln, eds., 443-466. Thousand Oaks, CA: Sage.

Stevenson, William B. and Danna Greenberg

2000 'Agency and social networks: Strategies of action in a social structure of position, opposition and opportunity’. Administrative Science Quarterly 45: 651-678.

Suddaby, Roy and Royston Greenwood

2006 'Institutional Entrepreneurship in Mature Fields: The Big Five Accounting Firms'. Academy of Management Journal 49/1: 27-48.

Toumey, Christopher

2005 'Apostolic succession: Does nanotechnology descend from Richard Feynman's 1959 talk?’ Engineering and Science 68: 16-23.

Toumey, Christopher

2007 'The man who understood the Feynman machine'. Nature Nanotechnology 2/1: 910 .

Toumey, Christopher

2008 'Reading Feynman into nanotechnology: A text for a new science'. Techne: Research in Philosophy and Technology 12/3: 133-168. 
Washington, Marvin

2004 'Field approaches to institutional change: The evolution of the National Collegiate Athletic Association’. Organization Studies 25/3: 393-414.

Whittle, Andrea

2008 'From flexibility to work-life balance: Exploring the changing discourses of management consultants’. Organization 15/4: 513-534.

Zbaracki, Mark

1998 'The rhetoric and reality of total quality management'. Administrative Science Quarterly 53/4: 719-744. 
Table 1: Description of the data and evidence of framing

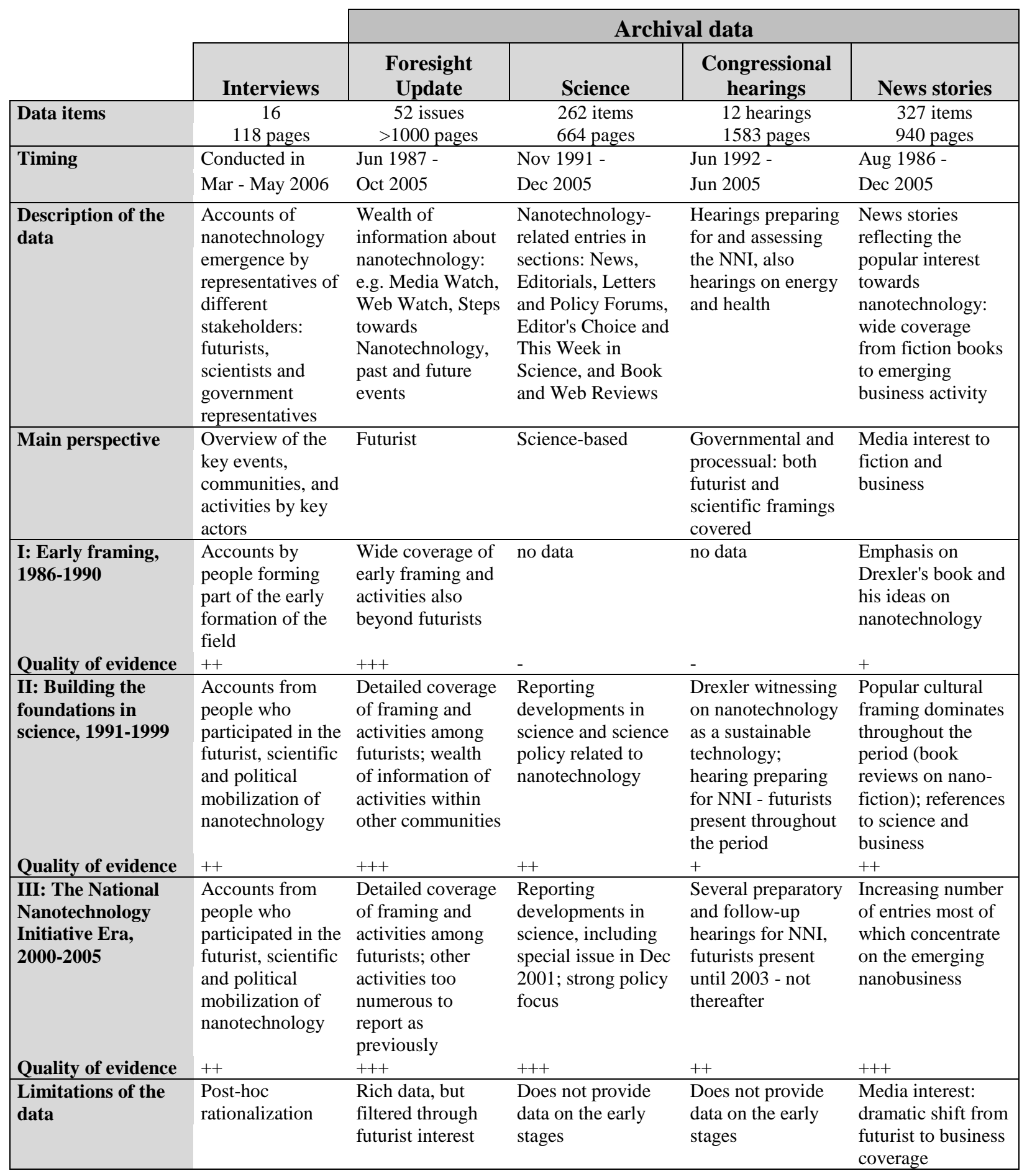

Quality of evidence on each framing period: - no data, + suggestive, ++ moderate, +++ strong 
Table 2: Chronology of the development of the nanotechnology field in US

\begin{tabular}{|c|c|c|c|}
\hline \multicolumn{2}{|c|}{ Futurist and science fiction communities } & \multicolumn{2}{|c|}{ Science and policy communities } \\
\hline 1959 & Feynman's speech There is Plenty of Room at the Bottom & & \\
\hline 1966 & Movie Fantastic Voyage & 1974 & The term nanotechnology introduced by Taniguchi \\
\hline 1975 & Founding of the L5 Society & 1978 & Supramolecular chemistry (Lehn) \\
\hline 1981 & $\begin{array}{l}\text { Drexler's article Molecular engineering: An approach to } \\
\text { the development of general capabilities for molecular } \\
\text { manipulation }\end{array}$ & 1981 & Scanning tunneling microscope (Rohrer and Binnig) \\
\hline 1984 & Lecture series on nanotechnology at MIT (Drexler) & & \\
\hline 1985 & Founding Nanotechnology Study Group at MIT & 1985 & C60 fulleren (Smalley, Curl and Kroto) \\
\hline 1986 & $\begin{array}{l}\text { Launch of nanotechnology in the book Engines of } \\
\text { Creation }\end{array}$ & 1986 & Atomic force microscope (Binnig, Quate and Gerber) \\
\hline & (Drexler), and founding of Foresight Institute & 1987 & First single electron transistor (Fulton and Dolan); \\
\hline 1987 & Quarterly publication of Foresight Update begins & & establishment of MEMS as a field; first size-based \\
\hline 1988 & $\begin{array}{l}\text { Course Nanotechnology and explorative engineering at } \\
\text { Stanford }\end{array}$ & & formulation of nanotechnology for science funding in UK \\
\hline 1989 & First Foresight conference & 1989 & The word IBM written with 35 atoms (Eigler) \\
\hline 1990 & $\begin{array}{l}\text { Drexler and Peterson speak in World Economic Forum in } \\
\text { Davos; Drexler participates in the OTA study on } \\
\text { miniaturization }\end{array}$ & 1990 & $\begin{array}{l}\text { The first academic journal Nanotechnology; NSF funding } \\
\text { for nanotechnology }\end{array}$ \\
\hline 1991 & Establishment of Institute for Molecular Manufacturing & 1991 & $\begin{array}{l}\text { Carbon nanotubes (Ijima); Science special issue on } \\
\text { nanotechnology }\end{array}$ \\
\hline 1992 & $\begin{array}{l}\text { Drexler's Nanosystems wins the annual awards for best } \\
\text { computer science book; Drexler testifies in the } \\
\text { Congressional hearing on New technologies for a } \\
\text { sustainable world }\end{array}$ & 1992 & Nanotechnology initiative at Rice University (Smalley) \\
\hline 1993 & Foresight Institute launches the Feynman Prize & 1995 & RAND Corporation report The Potential of \\
\hline 1995 & $\begin{array}{l}\text { Smalley and Stoddard as keynote speakers at the Fourth } \\
\text { Foresight Conference on Molecular Nanotechnology }\end{array}$ & & $\begin{array}{l}\text { Nanotechnology for Molecular Manufacturing; Naval } \\
\text { Research Laboratory report Nanoscience and } \\
\text { Nanotechnology in Europe }\end{array}$ \\
\hline 1996 & $\begin{array}{l}\text { Launch of the Feynman Grand Prize for Major Advances } \\
\text { in Molecular Nanotechnology }\end{array}$ & 1996 & $\begin{array}{l}\text { Rice Center for Nanoscale Science \& Technology } \\
\text { (Smalley); Smalley wins Nobel Prize }\end{array}$ \\
\hline 1997 & $\begin{array}{l}\text { Foresight Institute establishes an office in London; } \\
\text { founding of Zyvex, a Foresight affiliated firm }\end{array}$ & 1998 & $\begin{array}{l}\text { Launch of Interagency Working Group on } \\
\text { Nanotechnology, NSF and IWGN forum From Scientific }\end{array}$ \\
\hline 1998 & $\begin{array}{l}\text { NSF and IWGN sponsor a forum From Scientific } \\
\text { Discovery to the Nanotechnology of Tomorrow in } \\
\text { conjunction with the Sixth Foresight Conference }\end{array}$ & & $\begin{array}{l}\text { Discovery to the Nanotechnology of Tomorrow; } \\
\text { symposium on Device Applications of Nanoscale } \\
\text { Materials }\end{array}$ \\
\hline 1999 & $\begin{array}{l}\text { Ralph Merkle witnesses in the Congressional hearing on } \\
\text { the State of Nanoscience }\end{array}$ & 1999 & $\begin{array}{l}\text { Congressional hearing Nanotechnology: The State of } \\
\text { Nanoscience and Its Prospects for the Next Decade; } \\
\text { IWGN and NSF workshop Vision for Nanotechnology } \\
\text { R\&D in the Next Decade; IWGN report Nanostructure } \\
\text { Science and Technology: A Worldwide Study. }\end{array}$ \\
\hline 2000 & $\begin{array}{l}\text { Joy's article in Wired Why the Future Doesn't Need Us; } \\
\text { Foresight Guidelines on Molecular Nanotechnology; } \\
\text { National Medal of Technology to Ray Kurzweil }\end{array}$ & 2000 & $\begin{array}{l}\text { President Clinton announces the National Nanotechnology } \\
\text { Initiative, Science special issue on nanotechnology } \\
\text { Scientific American special issue on nanotechnology }\end{array}$ \\
\hline 2001 & $\begin{array}{l}\text { Publication of Prey by Michael Crichton; over } 500 \text { people } \\
\text { participate in the Ninth Foresight Conference on } \\
\text { Molecular Nanotechnology }\end{array}$ & 2003 & $\begin{array}{l}\text { Greenpeace report Future Technologies, Today's Choice, } \\
\text { Congressional Hearing Societal Implications of } \\
\text { Nanotechnology, Drexler-Smalley debate; Enactment of }\end{array}$ \\
\hline 2002 & $\begin{array}{l}\text { White paper Balancing the National Nanotechnology } \\
\text { Initiative’s R\&D Portfolio }\end{array}$ & & $\begin{array}{l}\text { the 21st Century Nanotechnology Research and } \\
\text { Development Act }\end{array}$ \\
\hline 2003 & $\begin{array}{l}\text { Report The Big Down by ETC; Peterson and Kurzweil } \\
\text { testify in the Congressional hearing on Societal } \\
\text { implications of nanotechnology } \\
\text { Launch of the New Foresight }\end{array}$ & 2004 & $\begin{array}{l}\text { IEEE Technology and Society Magazine special issue on } \\
\text { nanotechnology }\end{array}$ \\
\hline
\end{tabular}


Table 3: Development of the master frames

\begin{tabular}{|c|c|c|c|}
\hline Period & $\begin{array}{l}\text { Status of } \\
\text { the Field }\end{array}$ & Futurist community & Scientific community \\
\hline $\begin{array}{l}1986 \text { to } \\
\text { early } 1990 \text { s }\end{array}$ & Anticipated & $\begin{array}{l}\text { MASTER FRAME: Development in miniaturization will } \\
\text { inevitably give rise to Molecular Nanotechnology with great } \\
\text { possibilities and tremendous risks; an engineering vision with } \\
\text { focus on self-replicating, intelligent nanomachines. } \\
\text { Molecular assemblers will bring a revolution without parallel } \\
\ldots \text { The resulting nanotechnology can help life spread beyond } \\
\text { Earth ... it can help mind emerge in machines ... and it can let } \\
\text { our minds renew and remake our bodies... These revolutions } \\
\text { will bring dangers and opportunities too vast for the human } \\
\text { imagination to grasp. } \\
\text { - Drexler in Engines of Creation (1986), Chapter } 2\end{array}$ & $\begin{array}{l}\text { MASTER FRAME: Nanotechnology represents an } \\
\text { evolutionary continuation of miniaturization beyond the size } \\
\text { scale of a micron across natural sciences. } \\
\text { "Funds are now available through the National Physical } \\
\text { Laboratory ... for the support of projects which will lead to the } \\
\text { commercial exploitation of nanotechnology techniques. } \\
\text { Nanotechnology covers the manufacture and measurement ... } \\
\text { in the range } 0.1 \text { to } 100 \text { nm." - IEE News, October } 1987\end{array}$ \\
\hline $\begin{array}{l}\text { Early } \\
1990 \text { s to } \\
1999\end{array}$ & Emergent & $\begin{array}{l}\text { MASTER FRAME: Rather than everything in the particular } \\
\text { size scale, Molecular Nanotechnology refers to the future } \\
\text { developments of molecular machinery to perform } \\
\text { mechanosynthesis for molecular manufacturing. } \\
\text { The term nanotechnology is here used to refer to an } \\
\text { anticipated technology giving thorough control of the } \\
\text { structure of matter at the molecular level. This involves } \\
\text { molecular manufacturing, in which materials and products } \\
\text { are fabricated by the precise positioning of molecules in } \\
\text { accord with explicit engineering design. } \\
\text { - Drexler in Foresight Update 15, } 15 \text { Feb } 1993\end{array}$ & $\begin{array}{l}\text { MASTER FRAME: Nanotechnology represents a } \\
\text { revolutionary continuation of miniaturization beyond the size } \\
\text { scale of a micron across natural sciences. } \\
\text { We are about to enter a golden new era. .... These little nano } \\
\text { things and the technology that assembles and manipulates } \\
\text { them, what we call nanotechnology, will, I am certain, } \\
\text { revolutionize our industries and our lives. - Richard Smalley, } \\
\text { Congressional Hearing on 'The State of Nano-Science and its } \\
\text { Prospects for the Next Decade', } 22 \text { Jun } 1999 .\end{array}$ \\
\hline $\begin{array}{l}2000 \text { to } \\
2005\end{array}$ & Established & $\begin{array}{l}\text { MASTER FRAME: Molecular Nanotechnology refers to the } \\
\text { benefits and future potential of nanotechnology. This implies } \\
\text { de-emphasizing the idea of self-replicating machines. } \\
\text { We are staying true to the original goals of Foresight, but } \\
\text { putting them in a new context. As a think tank and public } \\
\text { interest organization, to flourish at this stage in the field's } \\
\text { development, it is essential that we bring value to an } \\
\text { expanding community of stakeholders and interested parties. } \\
\text { To establish a foundation for this, we have re-articulated our } \\
\text { mission: To ensure the beneficial implementation of } \\
\text { nanotechnology. - Foresight Update 55, } 13 \text { Oct } 2005 \text {. }\end{array}$ & $\begin{array}{l}\text { MASTER FRAME: Nanotechnology represents a } \\
\text { revolutionary continuation of miniaturization beyond the size } \\
\text { scale of a micron across natural sciences. Possibilities and } \\
\text { risks are to be addressed strictly within the boundaries of } \\
\text { natural laws. } \\
\text { Nanotechnology is the understanding and control of matter at } \\
\text { dimensions between approximately } 1 \text { and } 100 \text { nanometers, } \\
\text { where unique phenomena enable novel applications. } \\
\text { Encompassing nanoscale science, engineering, and } \\
\text { technology, nanotechnology involves imaging, measuring, } \\
\text { modeling, and manipulating matter at this length scale. } \\
\text { - The official National Nanotechnology Initiative definition }\end{array}$ \\
\hline
\end{tabular}


Figure 1: Distribution of news articles on nanotechnology in major US newspapers,

1986-2005, by the indicated focal actor, $N=327$

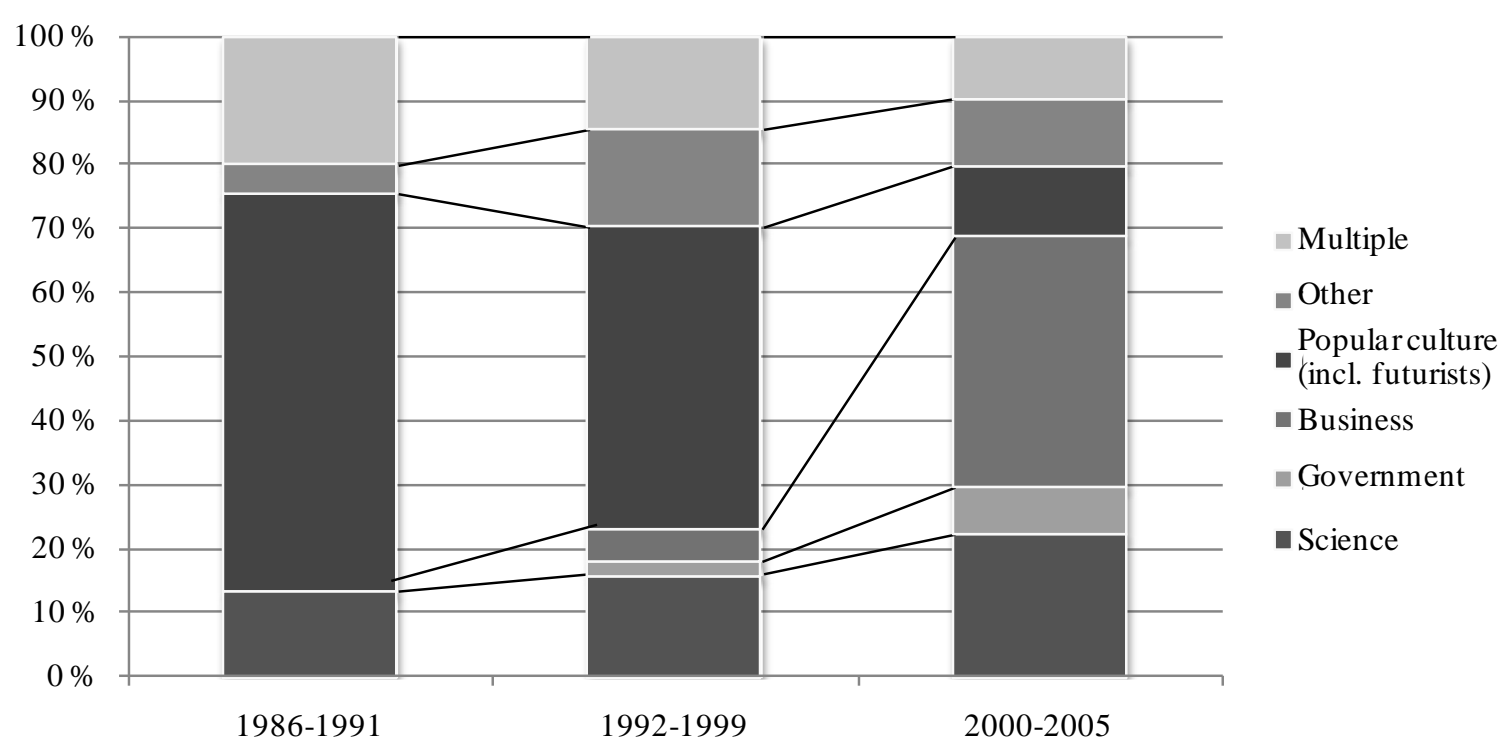




\section{Nina Granqvist}

Nina Granqvist is an Academy of Finland Research Fellow at Aalto University School of Economics. Her research interests include different approaches to the emergence of technological and scientific fields, including symbolic management, identity, social construction of technology, and agency in institutional fields. She focuses particularly on studying the processes that contribute to the formation of nanotechnology as a business and science. Her research has been published in Scandinavian Journal of Management and Academy of Management Best Paper Proceedings, and recognized with the EGOS Conference Best Paper Award.

\section{Juha Laurila}

Juha Laurila is a chaired Professor of Management and Organization at the Turku School of Economics. His research especially focuses on actor-focused approaches on organizational innovation and change. His publications include articles in journals such as the Journal of Management Studies, Organization Studies, Journal of Business Ethics, The International Journal of Human Resource Management, and Science, Technology and Human Values. He is also the author of Managing Technological Discontinuities and the co-editor of Technological Change and Organizational Action (both Routledge, 1998 and 2003).

\footnotetext{
Notes

${ }^{1}$ We are aware of the possibility for even a longer list of search words covering various labels of nanotechnology research and development (e.g. Heinze 2004). However, those adopted refer to the concepts that are shared among the key communities (futurists, scientists, and government representatives) who participated in the framing or legitimation of the nanotechnology field. Therefore, these search words give us access to the documents that are most relevant to the issue explored in this study.

${ }^{2}$ For the Congressional hearings the search word "nano" allowed us to include into our search all the words using this prefix, such as nanoscience and nanoscale. In contrast, using "nano" as the search word for scientific journals would return all the documents having e.g. the word nanometer; a common measure natural sciences, and in media where the word refers to names and places, resulting in an overwhelming amount of irrelevant documents. This warrants the use of different search words for varying data sources.

${ }^{3}$ An example of such use includes, "Will this Nation be the leader or just an observer in the next technological revolution, involving the confluence of bio, nano, and information technologies?” (Hearing 2863)

${ }^{4}$ According to the Moore's Law (a rule of thumb rather than a natural law), the number of transistors on a chip doubles about every two years [http://www.intel.com/technology/mooreslaw/].

${ }^{5}$ According to the SciFan website these are: Man Who Japed by Philip K. Dick in 1956; Beware the Microbots by Kurt Mahr in 1973; Ice Dragon by Jeffrey Lord and The Micro-Techs by Clark Darlton in 1974; Specimens by Fred Saberhagen in 1976; ORA:CLE by Kevin O'Donnell, Jr. in 1984; Blood Music by Greg Bear in 1985; and Lords of the Middle Dark by Jack L. Chalker in 1986. [http://www.scifan.com/themes/themes.asp?Th_themeid=13\&Page=1\&Items=30; accessed on 4 Nov, 2010] ${ }^{6}$ Japanese Professor Norio Taniguchi used the concept nanotechnology for the first time in 1974, but it was reinvented by Drexler and his associates in the 1980s.

${ }^{7}$ These include Tom Kalil from Clinton administration, Mike Roco from NSF, Neil Lane from the Office of Science and Technology Policy, and Jim Murday from the Office of Naval Research.
} 